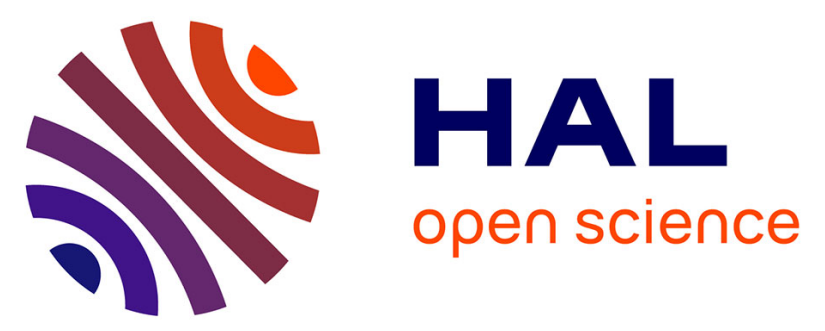

\title{
Multimodal Remote Monitoring of High Cardiovascular Risk Patients With OSA Initiating CPAP A Randomized Trial
}

Jean-Louis Pépin, Ingrid Jullian-Desayes, Marc Sapène, Erika Treptow, Marie Joyeux-Faure, Meriem Benmerad, Sébastien Bailly, Yves Grillet, Bruno Stach, Philippe Richard, et al.

\section{To cite this version:}

Jean-Louis Pépin, Ingrid Jullian-Desayes, Marc Sapène, Erika Treptow, Marie Joyeux-Faure, et al.. Multimodal Remote Monitoring of High Cardiovascular Risk Patients With OSA Initiating CPAP A Randomized Trial. Chest, 2019, 155, pp.730 - 739. 10.1016/j.chest.2018.11.007 . hal-03486814

\section{HAL Id: hal-03486814 https://hal.science/hal-03486814}

Submitted on 20 Dec 2021

HAL is a multi-disciplinary open access archive for the deposit and dissemination of scientific research documents, whether they are published or not. The documents may come from teaching and research institutions in France or abroad, or from public or private research centers.
L'archive ouverte pluridisciplinaire HAL, est destinée au dépôt et à la diffusion de documents scientifiques de niveau recherche, publiés ou non, émanant des établissements d'enseignement et de recherche français ou étrangers, des laboratoires publics ou privés.

\section{(ㅇ)(1) $\$$}

Distributed under a Creative Commons Attribution - NonCommerciall 4.0 International 


\section{Multimodal remote monitoring of high cardiovascular risk OSA patients initiating CPAP: a randomized trial}

Jean-Louis Pépin MD, $\mathrm{PhD}^{1,2}$, Ingrid Jullian-Desayes PharmD, $\mathrm{PhD}^{1,2}$, Marc Sapène $\mathrm{MD}^{3}$, Erika Treptow MD, PhD ${ }^{1,2}$, Marie Joyeux-Faure PharmD, PhD ${ }^{1,2}$, Meriem Benmerad $\mathrm{MSc}^{1,2}$, Sébastien Bailly PharmD, PhD ${ }^{1,2}$, Yves Grillet MD ${ }^{4}$, Bruno Stach $\mathrm{MD}^{5}$, Philippe Richard MD ${ }^{6}$, Patrick Lévy MD, PhD ${ }^{1,2}$, Jean-François Muir MD ${ }^{7}$, Renaud Tamisier MD,PhD ${ }^{1,2}$

1. HP2 laboratory, INSERM U1042, Grenoble Alpes University, Grenoble, France

2. EFCR laboratory, Pole Thorax and Vessels, Grenoble Alps University Hospital, Grenoble, France

3. Private practice sleep and respiratory disease center, Nouvelle Clinique Bel Air, Bordeaux, France

4. Private practice sleep and respiratory disease center, Valence, France

5. Private practice sleep and respiratory disease center, Valenciennes, France

6. Private practice sleep and respiratory disease center, Saint Omer, France

7. Rouen University Hospital, Bois Guillaume, France

Running Head: multimodal telemonitoring in OSA

Corresponding author and guarantor of the manuscript

Pr Jean-Louis PEPIN

Laboratoire EFCR

$\mathrm{CHU}$ de Grenoble

CS10217

38043 Grenoble Cedex 9

Email: JPepin@chu-grenoble.fr

Main text Word count: 2499

Authors' contributions: J-LP, IJ-D, RT, PL and MJ-F contributed substantially to the study design, data collection and interpretation. $\mathrm{MB}$ and $\mathrm{SB}$ performed the statistical analysis. MS, ET, YG, BS, PR, and J-FM included patients and collected data. MJ-F, IJ-D and J-LP wrote the article and SB, MB, RT, MS, ET, YG, BS, PR, PL, and J-FM critically revised the manuscript.

Responsibility for Data: J-LP had full access to all the data in the study and takes responsibility for the integrity of the data and the accuracy of the data analysis, including and especially any adverse effects. J-LP takes full responsibility for the integrity of the submission as a whole, from inception to published article

Conflict of interest: JLP, RT report a grant from a consortium of homecare providers (ADIR assistance, Agiradom, IPS ISIS medical, LINDE, LVL medical, SOS oxygen, Vitalairea) and CPAP companies (Bréas, Philips, Resmed and Sefam), during the conduct of the study; grants from Philips, RESMED, Fisher and Paykel, Fondation de la recherche medicale, Direction de la recherche Clinique du CHU de Grenoble, Fond de dotation "Agir pour les maladies chroniques"., personal fees from Perimetre, Philips, Fisher and Paykel, RESMED, Astra-Zeneka and SEFAM, Agiradom, ELIA, Teva, outside the submitted work. SB,IJD, MJF, MB, MS, ET, YG, BS, PR, PL, and J-FM have nothing to declare. 
Funding: The study was funded by an unrestricted grant from a consortium of home care providers (ADIR assistance, Agiradom, IPS, ISIS medical, LINDE, LVL medical, SOS oxygen, Vitalaire) and CPAP companies (Bréas, Philips, Resmed and Sefam). It was an academic study with the French national federation of Pneumology acting as the sponsor. JLP, IJD, MJF, RT and SB are supported by the French National Research Agency in the framework of the "Investissements d'avenir" program (ANR-15-IDEX-02).

\section{Abbreviations}

AHI Apnea + Hypopnoea Index

BP Blood pressure

CPAP Continuous positive airway pressure

DHBP Diastolic home self-measured blood pressure

\section{ESS Epworth Sleepiness Scale}

HBP Home self-measured blood pressure

IQR Interquartile range

ITT Intention-to-treat

OSA Obstructive sleep apnea

RCT Randomized controlled trial

SD Standard deviation

SHBP Systolic home self-measured blood pressure 


\section{Abstract (250 words)}

Background: The management of patients with high cardiovascular risk and obstructive sleep apnea (OSA) must target not only improving adherence to continuous positive airway pressure (CPAP) but should also include strategies aimed at reducing blood pressure (BP) and increasing physical activity. The study aims to evaluate the effectiveness of an integrated intervention using remote patient telemonitoring in reducing BP in high cardiovascular risk OSA patients.

Methods: In a multicenter, open, randomized trial, OSA patients were randomly assigned at CPAP initiation to usual care or multimodal telemonitoring for 6 months. Telemonitoring used electronic equipment collecting information about BP, symptoms, CPAP side effects and physical activity with home care providers pre-specified protocoled actions. The primary effectiveness outcome was assessed using home self-measured BP (HBP) on 3 consecutive days. Secondary outcomes included CPAP compliance, symptoms and physical activity.

Results: Of 306 patients aged 61.3 [54.1;66.1] (median [IQR]) years; predominantly male 226 (74\%) with a body mass index of 32.0 [28.7;35.6] kg/m² and an apnea hypopnea index of 46 [35;61] events/hour, 149 received usual care and 157 telemonitoring. After 6 months of CPAP, HBP did not differ significantly between groups. In secondary analyses, there was no significant difference in steps per day, but a significant increase in CPAP adherence, and an improvement in daytime sleepiness and quality of life in favor of the multimodal telemonitoring.

Conclusion: In OSA patients with high cardiovascular risk, multimodal telemonitoring was not superior to usual CPAP care for improving home blood pressure. However, telemonitoring improved adherence and patient-centered outcomes. 


\section{Introduction}

Obstructive sleep apnoea (OSA) is characterized by repeated episodes of apnoeas and hypopnoeas during sleep producing intermittent hypoxia and sleep fragmentation. ${ }^{1}$ OSA is associated with hypertension, arrhythmias, stroke, coronary heart disease, and increased cardiovascular mortality. ${ }^{2}$ Meta-analyses have demonstrated that continuous positive airway pressure (CPAP), the first line treatment for OSA, reduces 24-hour mean blood pressure (BP) by about $2 \mathrm{mmHg} \cdot{ }^{3-5}$ An improvement in BP and cardiac outcomes tended to occur only in OSA patients with CPAP adherence of at least 4 hours/night. ${ }^{6}$ In observational cohort studies, CPAP had initially been suggested as being able to reduce cardiovascular events. ${ }^{7,8}$ However, data from large randomized controlled trials (RCTs) currently do not support a role for CPAP alone in reducing cardiovascular mortality. ${ }^{2,9}$ The interpretation of recent studies is that OSA management in patients at high cardiovascular risk should include further consideration of individual risk factors, use of new multimodality therapies addressing lifestyles ${ }^{10,11}$ and as well as concentrating on CPAP adherence. ${ }^{2}$

Optimizing CPAP adherence remains a challenge with only $50-60 \%$ of patients remaining adherent months after initiation. ${ }^{12,13}$ CPAP telemonitoring has recently been proposed as a technological advance to improve adherence and early detection of CPAP-associated problems. ${ }^{14,15}$ Beyond CPAP usage and signaling of device problems, remote telemonitoring allowing scrutiny of individual patient's risks by using connected devices measuring physical activity and BP appears an attractive option. In this study, we considered how CPAP telemonitoring might be extended to encompass the patient's cardio-metabolic health providing personalized care and multi-disease management to high cardiovascular risk OSA patients.

The OPTISAS 2 study aims to evaluate the impact of multimodal telemonitoring collecting not only CPAP adherence and side effects but also information about BP, symptoms and steps/day in comparison to usual CPAP care, in a RCT with systolic home self-measured BP (HBP) as the primary outcome. Secondary outcomes were CPAP adherence, diastolic HBP, daytime sleepiness, fatigue, quality of life, and physical activity.

\section{Methods}




\section{Study design and participants}

This multicenter, open, RCT compared the modification of 6-month systolic BP after allocation of OSA patients at high cardiovascular risk to usual CPAP care group or a group with multidisciplinary and coordinated follow-up based on telemonitoring. This study was conducted in accordance with applicable good clinical practice requirements in Europe, French law, ICH E6 recommendations, and the ethical principles of the Helsinki Declaration (South Africa 1996 and Edinburgh 2000). The trial was approved by an independent ethics committee (Comité de Protection des Personnes Sud Est V, Grenoble, France, $\mathrm{N}^{\circ}$ IRB: 0006705) and registered on the ClinicalTrials.gov site (NCT: 01505959).

There were 32 recruiting French centers from February 2013 to October 2013, Grenoble as coordinating center. All centers were sleep units with facilities for diagnosis, treatment and follow-up of OSA, and had worked with professional home-care providers trained in CPAP initiation and follow-up.

Eligible patients were aged 18 to 75 years, with severe OSA (apnoea+hypopnoea index (AHI)>30 events/hour) based on respiratory polygraphy or polysomnography. Patients should suffer from at least one cardiovascular disease or exhibit an elevated cardiovascular risk assessed by the ten-year risk of fatal cardiovascular event SCORE calculation established specifically for European countries. ${ }^{16}$ Patients with a SCORE risk $>5 \%$ at 10 years or in secondary prevention were included. Patients with central sleep apnoea or heart failure with a left ventricular ejection fraction $<40 \%$ were excluded.

\section{Intervention}

The patients were treated by auto-CPAP with a pressure window between 6 and $14 \mathrm{cmH} 20$. Both usual care and remote multimodal telemonitoring arms received the same 1-hour CPAP initiation educational program. The multimodal telemonitoring (Figure 1) included systolic and diastolic HBP and physical activity recorded by connected devices. This assessment of individual risk was associated with CPAP telemonitoring providing adherence, leaks, and residual events. Symptoms and quality of life were recorded via electronic questionnaires to be filled-in by patients. Patients benefited from a demonstration of how to use the remote home telemonitoring equipment and an 
explanation of why monitoring physiological variables is relevant for their care. Concerning HBP recommendations, patients had to perform 3 measurements in the morning and the evening for 3 consecutive days in both groups. One minute was required between each measurement and the patient had to stay sedentary before and during the measurements.

Secured data transmission from the physiological sensors and patient reported outcomes to the medical staffs' computers and secured websites allowed for easy telemonitoring, providing a complete integrated care management system.

Automatic algorithms were constructed for the prompt adjustment of CPAP treatment in the event of side effects, leaks (specific thresholds depending upon the CPAP device brand), residual sleepiness (ESS> 10) or persistent residual events (residual $\mathrm{AHI}>10 /$ hours). For the main side effects (aerophagia, dry mouth, abrasion of the ridge of the nose, sneezing and nasal drip, ${ }^{17}$ specific and homogeneous procedures had been defined prior to the study and agreed between the different study sites. The addition of humidifiers, changes in the interfaces and reductions in pressure were among the most frequently proposed actions. In CPAP adherent patients, for those with persistent sleepiness or residual respiratory events above 10/hour, a sleep study under CPAP was generally scheduled. The efficacy of such actions was systematically assessed by asking patients to report any new or persistent side effects and patient centered outcomes via electronic questionnaires generated by the web platform. The multimodal telemonitoring system allocated predefined interventions to home-care providers (managing leaks, mask problems or other side effects). Physicians were in charge of the appropriate management of residual events or CPAP lack of efficacy. Additional home visits or to the sleep clinic were organized when required.

\section{Randomization and masking}

Participants were randomized to multimodal remote telemonitoring or usual care (1:1 ratio) using computergenerated allocation. Randomization was stratified by center, home-care provider and CPAP brand ( 4 main brands used in France). 
Neither participants nor investigators were masked to group assignment. BP measurements used the automatic mode of the sphygmomanometer without the need for intervention by an investigator. Patient outcomes (sleepiness, fatigue, depression, and side effects) were recorded at home without investigators' intervention. All data of the study were analyzed by personnel blinded to group allocation.

\section{Procedures}

Assessments for the primary and secondary outcome were done immediately before CPAP initiation and after 6 months of treatment. The multimodal telemonitoring arm included additional regular assessments at day 8, and months 1 and 6

Home self-measurement of blood pressure (HBP)

HBP is nowadays the preferred method for the accurate measurement of BP with superiority compared to office

BP. ${ }^{18,19}$ Its prognostic value is comparable to 24-hour ambulatory BP monitoring and superior to office measurements according to a meta-analysis investigating the association of HBP measurements with target organ damage in hypertension. ${ }^{20} \mathrm{HBP}$ is easier to implement, cost-effective, and engages and empowers patients. Each sequence of HBP measurements was conducted during 3 consecutive days ( 3 measurements in the morning and 3 in the evening, i.e. 18 measurements).

Physical activity

An actimeter was fitted to the patient's arm during 3 days before CPAP initiation and after 6 months of treatment.

Questionnaires

Quality of life, health status, fatigue, and sleepiness were evaluated using the SF-12, ${ }^{21}$ Pichot questionnaires (fatigue and depression $)^{22}$ and the Epworth Sleepiness Scale (ESS) ${ }^{23}$ respectively, at inclusion and at 6 months.

Biological parameters

Cholesterol (total, LDL and $\mathrm{HDL}$ ), fasting glucose and $\mathrm{HbA1c}$ were measured to calculate the cardiovascular risk at inclusion and 6 months of treatment. 


\section{Outcomes}

The joint primary outcomes at 6 months were: change in morning and evening systolic HBP in the telemonitoring arm compared to usual care. We used SBP as the primary outcome in our study as it has previously been frequently used in studies comparing CPAP with an inactive control (44 studies in the meta-analysis by Bratton et $\mathrm{al}^{5}$ ). This outcome is relevant as it is related to mortality and the incidence of late cardiovascular events ${ }^{24}$. Secondary outcomes at 6 months were CPAP adherence, change in morning and evening diastolic HBP and changes in subjective sleepiness (ESS), fatigue, quality of life, physical activity, lipids and glucose metabolism.

\section{Sample size calculation}

The hypothesis was that BP improvement after 6 months of CPAP treatment would be greater in the multimodal telemonitoring arm compared with usual CPAP care. In the study by MacManus et al. ${ }^{25}$ conducted in severe hypertensive patients, a $3.3 \mathrm{mmHg}$ difference was observed between the self-management of hypertension in combination with telemonitoring and standard care arms. ${ }^{25}$ As CPAP is less effective than antihypertensive agents in reducing $\mathrm{BP}$ we expected a mean reduction of $2.3 \mathrm{mmHg} .{ }^{26}$ On the assumption of a SD of $11.9 \mathrm{mmHg}$, and $10 \%$ dropout, a sample size of 468 participants per group was required to detect a difference of at least $2.3 \mathrm{mmHg}$ between groups with $80 \%$ power. The study was powered on the primary analysis alone.

\section{Statistical analysis}

Data were initially analyzed in intention-to-treat (ITT) including all randomized patients. Then, a per-protocol analysis was done on all randomized subjects excluding study dropouts.

To replace missing data, multiple imputations were performed for the primary outcomes by using a logistic and linear regression model for binary or continuous variables respectively. Fifty datasets were constituted.

Continuous data are presented as mean \pm standard deviation (SD) or median with interquartile range (IQR) and categorical data as frequency and percentage. Normality was assessed using Skewness and Kurtosis tests. 
A linear mixed effects model, with random effect by homecare provider was used to analyze the main and the secondary objectives. We analyzed the difference between 6-month and baseline values by group with adjustment on baseline values of the analyzed variable. When the conditions for use of the linear mixed model were not respected a non-parametric Mann-Witney test was performed.

For compliance, because there was no baseline value, only the random effect was considered in the linear mixed model. Statistical analyses were performed by using SAS V9.4 (SAS Institute Inc., Cary, NC, USA). A p-value<0.05 was considered as significant.

\section{Results}

At baseline, 306 patients were randomized: 157 to telemonitoring and 149 to usual care (Figure 2). Patients were predominantly male 226 (74\%) aged 61.3 [54.1;66.1] years (median [IQR]); with a body mass index (BMI) of 32.0 $[28.7 ; 35.6] \mathrm{kg} / \mathrm{m}^{2}$ and a $\mathrm{AHI}$ of $46[35 ; 61]$ events/hour. Data for each group are reported in Table 1 . No differences were found between the two arms regarding sleep apnea severity evaluated by polysomnography or by respiratory polygraphy.

Primary outcome: Home self-measured blood pressure (HBP)

There was no difference between the multimodal telemonitoring group and the usual care group for the primary outcome: systolic HBP. In ITT analysis, morning systolic and diastolic HBP, as well as the evening diastolic HBP were significantly lower in both arms after 6 months of CPAP treatment. No difference in the evening systolic HBP was observed after CPAP treatment (Figure 3 and Table 2). Per-protocol analysis did not change these results.

Secondary outcomes

Physical activity

Physical activity (mean number of steps/day) was not improved in either group after 6 months of CPAP treatment (Table 3).

Patients centered outcomes 
As shown in Figure 4 and Table 3, the ESS and Pichot fatigue scale significantly improved in both arms but the range of improvement was significantly higher for ESS in the multimodal telemonitoring intervention. The physical component of SF-12 indicated significantly greater improvement in the telemonitoring arm.

Biological parameters of cardio-metabolic risk

There was no difference between the multimodal telemonitoring group and the usual care group for biological parameters (Table 3). Total cholesterol and triglyceride levels were significantly lowered, and HDL-cholesterol improved after 6 months in the multimodal telemonitoring arm (Table 3). LDL-cholesterol significantly decreased in the usual follow-up group only. Moreover, BMI did not change after CPAP in either of the two arms.

CPAP adherence

In intention-to-treat analysis, CPAP compliance was significantly higher in the telemonitoring group than in the usual care group: $5.28 \pm 2.23$ versus $4.75 \pm 2.50$ hours respectively $(p=0.05)$.

\section{Discussion}

This was one of the largest RCTs in the field and the first investigating the CPAP impact and multimodal telemonitoring, with BP reduction as primary outcome. A strength was that the patients had a well-defined homogeneous phenotype of moderate to severe OSA with high cardiovascular risk, one of the major OSA phenotypes. ${ }^{27}$ As shown in the results, BMI did not change after CPAP treatment in either of the two arms confirming that BP evolution was not affected by body weight modifications. Our hypothesis was that providing patients with an integrated multimodal platform for monitoring and care would significantly enhance BP reduction. While our data showed that multimodal telemonitoring was not superior to usual CPAP for improving HBP in OSA patients with high cardiovascular risk, but it increased CPAP compliance and had a positive impact on patient centered outcomes.

In RCTs CPAP use has not lowered the rates of death or incident cardiovascular events. ${ }^{2,9,28,29}$ These negative results may be partly explained by the overall poor adherence; indeed at least 4 hours/night are required to improve cardiovascular outcomes. ${ }^{2,30}$ CPAP telemonitoring seems to be a good opportunity to improve CPAP adherence ${ }^{14,31}$ 
and appears a better choice than other methods such as simple educational video sessions about OSA and CPAP therapy that have not demonstrated superiority compared to usual care in patients at risk of poor CPAP adherence. ${ }^{32}$ In our study only the results of BP and physical activity telemonitoring were displayed to patients, without additional personalized coaching. Recent studies have reported that text messaging could double the odds of medication adherence in chronic diseases. ${ }^{33}$ Telemedical interventional management has also been tested in patients with heart failure $^{34}$. In OSA field, the tele-OSA study ${ }^{31}$ of automated messaging associated with telemonitoring gave early improvement in CPAP adherence but this effect gradually declined after discontinuation of automated feedback messaging. The addition of mobile e-health applications as adjuncts to basic telemonitoring encouraging active patient engagement led to a one hour mean increase in CPAP adherence. ${ }^{35}$ Taken together these data demonstrate an incremental efficacy of telemonitoring [0.5 hour in the current study] combined with text messaging and health technologies to empower patients. In line with this, another outcome was that multimodal telemonitoring not only improves CPAP adherence but also patient centered outcomes, namely sleepiness and quality of life. HBP decrease was not superior with multimodal telemonitoring compared to usual CPAP care in our high cardiovascular risk OSA patients. It may be argued that while we focused on CPAP use, our intervention lacked a personalized program to encourage physical activity, a key determinant of BP reduction, rather than simply monitoring activity. OSA patients show low levels of spontaneous physical activity ${ }^{35}$ and this does not improve with CPAP, despite a reduction in daytime sleepiness. ${ }^{37}$ In obese OSA patients on CPAP, non-invasive ventilation or respiratory muscle training as adjuncts to exercise have recently been shown to significantly reduce HBP. ${ }^{11}$ Moreover, weight loss plus CPAP have synergistic effects on BP compared to each intervention alone. ${ }^{10}$ These studies highlight the beneficial effects of lifestyle and risk factor management in reducing BP in comorbid OSA. The evidence supports a combined treatment strategy in obese OSA.

The main limitation of this study was the failure to reach the estimated sample size. During the course of the study reimbursement for telemonitoring was suspended in France owing to opposition to it by several patients' associations. For the first time the French healthcare authorities had attempted, by decree, to make coverage of 
health costs conditional on patient's adherence to treatment. Patients successfully appealed against this decree through the highest court "Conseil d'Etat". Consequently, the trial data monitoring committee recommended trial termination for pragmatic reasons. Furthermore, a post-hoc power analysis showed that, considering the small mean differences between the groups and the broad standard errors for the primary outcome $(-0.78$; IC 95\% $[-3.91 ; 2.35]$ $\mathrm{mmHg}$ and -0.01 ; IC 95\% [-3.10;3.06] mmHg for morning and evening HBP respectively) a sample of 16,202 patients would have been needed to reach a sufficient power of 0.8 to show a significant difference of $0.7 \mathrm{mmHg}$; which is not clinically relevant. Thus while large, the trial was not large enough, despite the involvement of 32 centers in private and public practice, 9 different home-care providers, allowing good generalization of the data. Moreover, the modest difference in CPAP adherence between the two arms was probably not enough to induce a significant reduction in blood pressure. In a recent meta-analysis, Bratton et al. ${ }^{5}$ showed that a 1-hour-per-night increase in mean CPAP use was associated with an additional reduction in systolic blood pressure of $1.5 \mathrm{mmHg}(95 \% \mathrm{Cl}, 0.8$ to $2.3 \mathrm{mmHg} ; P<$ $0.001)$ and an additional reduction in diastolic blood pressure of $0.9 \mathrm{~mm} \mathrm{Hg}(95 \% \mathrm{Cl}, 0.3$ to $1.4 \mathrm{~mm} \mathrm{Hg} ; P=0.001)$. Thus, the half-hour increase in CPAP adherence is statistically significant but of limited clinical relevance.

This impact of multimodal telemonitoring on patient-reported outcomes argues in favor of this type of management, but aspects such as privacy, shared decision making and healthcare coverage/reimbursement policies need to be taken into account. The reasons why we failed to achieve the targeted sample size need to be considered when designing future studies and introducing ICT technologies to monitor patient health at home.

\section{Conclusion and perspectives}

In OSA patients with high cardiovascular risk, multimodal telemonitoring was not superior to usual CPAP care for improving HBP but improved CPAP adherence and patient centered outcomes. Further studies should explore how multimodal telemonitoring can be associated with a personalized physical activity program and coaching, to improve patient engagement and empowerment. Additionally, cost-effectiveness studies are needed to establish the sustainability of new strategies of patient-centered care for OSA. 


\section{Acknowledgements}

We thank Alison Foote (Grenoble Alpes University Hospital) for critically editing the manuscript and HealthID for operational support during the trial.

\section{References}

1. Lévy P, Kohler M, McNicholas WT, et al. Obstructive sleep apnoea syndrome. Nat Rev Dis Primer 2015;1:15015.

2. Drager LF, McEvoy RD, Barbe F, Lorenzi-Filho G, Redline S, INCOSACT Initiative (International Collaboration of Sleep Apnea Cardiovascular Trialists). Sleep Apnea and Cardiovascular Disease: Lessons From Recent Trials and Need for Team Science. Circulation 2017;136(19):1840-1850.

3. Alajmi M, Mulgrew AT, Fox J, et al. Impact of continuous positive airway pressure therapy on blood pressure in patients with obstructive sleep apnea hypopnea: a meta-analysis of randomized controlled trials. Lung 2007;185(2):67-72.

4. Haentjens P, Van Meerhaeghe A, Moscariello A, et al. The impact of continuous positive airway pressure on blood pressure in patients with obstructive sleep apnea syndrome: evidence from a meta-analysis of placebocontrolled randomized trials. Arch Intern Med 2007;167(8):757-764.

5. Bratton DJ, Gaisl T, Wons AM, Kohler M. CPAP vs Mandibular Advancement Devices and Blood Pressure in Patients With Obstructive Sleep Apnea: A Systematic Review and Meta-analysis. JAMA 2015;314(21):2280-2293.

6. Abuzaid AS, Al Ashry HS, Elbadawi A, et al. Meta-Analysis of Cardiovascular Outcomes With Continuous Positive Airway Pressure Therapy in Patients With Obstructive Sleep Apnea. Am J Cardiol 2017;120(4):693-699.

7. Marin JM, Carrizo SJ, Vicente E, Agusti AGN. Long-term cardiovascular outcomes in men with obstructive sleep apnoea-hypopnoea with or without treatment with continuous positive airway pressure: an observational study. Lancet Lond Engl 2005;365(9464):1046-1053.

8. Marin JM, Agusti A, Villar I, et al. Association between treated and untreated obstructive sleep apnea and risk of hypertension. JAMA 2012;307(20):2169-2176.

9. McEvoy RD, Antic NA, Heeley E, et al. CPAP for Prevention of Cardiovascular Events in Obstructive Sleep Apnea. N Engl J Med 2016;375(10):919-931. 
10. Chirinos JA, Gurubhagavatula I, Teff K, et al. CPAP, weight loss, or both for obstructive sleep apnea. $N$ Engl J Med 2014;370(24):2265-2275.

11. Vivodtzev I, Tamisier R, Croteau M, et al. Ventilatory support or respiratory muscle training as adjuncts to exercise in obese CPAP-treated patients with obstructive sleep apnoea: a randomised controlled trial. Thorax 2018;

12. Rosen CL, Auckley D, Benca R, et al. A multisite randomized trial of portable sleep studies and positive airway pressure autotitration versus laboratory-based polysomnography for the diagnosis and treatment of obstructive sleep apnea: the HomePAP study. Sleep 2012;35(6):757-767.

13. Kribbs NB, Pack Al, Kline LR, et al. Objective measurement of patterns of nasal CPAP use by patients with obstructive sleep apnea. Am Rev Respir Dis 1993;147(4):887-895.

14. Pépin JL, Tamisier R, Hwang D, Mereddy S, Parthasarathy S. Does remote monitoring change OSA management and CPAP adherence? Respirol Carlton Vic 2017;22(8):1508-1517.

15. Liu D, Armitstead J, Benjafield A, et al. Trajectories of Emergent Central Sleep Apnea During CPAP Therapy. Chest 2017;152(4):751-760.

16. Conroy RM, Pyörälä K, Fitzgerald AP, et al. Estimation of ten-year risk of fatal cardiovascular disease in Europe: the SCORE project. Eur Heart J 2003;24(11):987-1003.

17. Pépin JL, Leger P, Veale D, Langevin B, Robert D, Lévy P. Side effects of nasal continuous positive airway pressure in sleep apnea syndrome. Study of 193 patients in two French sleep centers. Chest 1995;107(2):375-381.

18. Imai null, Ohkubo null, Sakuma null, et al. Predictive power of screening blood pressure, ambulatory blood pressure and blood pressure measured at home for overall and cardiovascular mortality: a prospective observation in a cohort from Ohasama, northern Japan. Blood Press Monit 1996;1(3):251-254.

19. Parati G, Stergiou GS, Asmar R, et al. European Society of Hypertension guidelines for blood pressure monitoring at home: a summary report of the Second International Consensus Conference on Home Blood Pressure Monitoring. J Hypertens 2008;26(8):1505-1526.

20. Bliziotis IA, Destounis A, Stergiou GS. Home versus ambulatory and office blood pressure in predicting target organ damage in hypertension: a systematic review and meta-analysis. J Hypertens 2012;30(7):1289-1299.

21. Ware J, Kosinski M, Keller SD. A 12-Item Short-Form Health Survey: construction of scales and preliminary tests of reliability and validity. Med Care 1996;34(3):220-233.

22. Pichot P. Un questionnaire d'auto-évaluation de la symptomatologie dépressive, le Questionnaire QD2: I. Construction, structure factorielle et propriétés métrologiques [A questionnaire for self-evaluation of depressive symptomatology, the QD2 Questionnaire: I. Construction, factorial structure and metrological properties.

23. Johns MW. A new method for measuring daytime sleepiness: the Epworth sleepiness scale. Sleep 1991;14(6):540-545.

24. Turnbull F. Effects of different blood-pressure-lowering regimens on major cardiovascular events: results of 
prospectively-designed overviews of randomised trials. Lancet 2003;362(9395):1527-35.

25. McManus RJ, Mant J, Bray EP, et al. Telemonitoring and self-management in the control of hypertension (TASMINH2): a randomised controlled trial. Lancet Lond Engl 2010;376(9736):163-172.

26. Hu X, Fan J, Chen S, Yin Y, Zrenner B. The role of continuous positive airway pressure in blood pressure control for patients with obstructive sleep apnea and hypertension: a meta-analysis of randomized controlled trials. J Clin Hypertens Greenwich Conn 2015;17(3):215-222.

27. Bailly S, Destors M, Grillet Y, et al. Obstructive Sleep Apnea: A Cluster Analysis at Time of Diagnosis. PloS One 2016;11(6):e0157318.

28. Barbe F, Duran-Cantolla J, Sanchez-de-la-Torre M, et al. Effect of continuous positive airway pressure on the incidence of hypertension and cardiovascular events in nonsleepy patients with obstructive sleep apnea: a randomized controlled trial. JAMA 2012;307(20):2161-8.

29. Peker Y, Glantz H, Eulenburg C, Wegscheider K, Herlitz J, Thunström E. Effect of Positive Airway Pressure on Cardiovascular Outcomes in Coronary Artery Disease Patients with Nonsleepy Obstructive Sleep Apnea. The RICCADSA Randomized Controlled Trial. Am J Respir Crit Care Med 2016;194(5):613-620.

30. Javaheri S, Barbe F, Campos-Rodriguez F, et al. Sleep Apnea: Types, Mechanisms, and Clinical Cardiovascular Consequences. J Am Coll Cardiol 2017;69(7):841-858.

31. Hwang D, Chang JW, Benjafield AV, et al. Effect of Telemedicine Education and Telemonitoring on CPAP Adherence: The Tele-OSA Randomized Trial. Am J Respir Crit Care Med 2017;

32. Guralnick AS, Balachandran JS, Szutenbach S, et al. Educational video to improve CPAP use in patients with obstructive sleep apnoea at risk for poor adherence: a randomised controlled trial. Thorax 2017;72(12):1132-1139.

33. Thakkar J, Kurup R, Laba T-L, et al. Mobile Telephone Text Messaging for Medication Adherence in Chronic Disease: A Meta-analysis. JAMA Intern Med 2016;176(3):340-349.

34. Koehler F, Koehler K, Deckwart O, et al. Efficacy of telemedical interventional management in patients with heart failure (TIM-HF2): a randomised, controlled, parallel-group, unmasked trial. Lancet Lond Engl 2018;392(10152):1047-1057.

35. Malhotra A, Crocker ME, Willes L, Kelly C, Lynch S, Benjafield AV. Patient Engagement Using New Technology to Improve Adherence to Positive Airway Pressure Therapy: A Retrospective Analysis. Chest 2017;

36. Mendelson M, Bailly S, Marillier M, et al. Obstructive Sleep apnea Syndrome, Objectively measured Physical activity and exercise training interventions: a Systematic Review and meta-analysis. 2018;

37. West SD, Kohler M, Nicoll DJ, Stradling JR. The effect of continuous positive airway pressure treatment on physical activity in patients with obstructive sleep apnoea: A randomised controlled trial. Sleep Med 2009;10(9):1056-1058. 
Table 1. Patients' characteristics at inclusion

\begin{tabular}{|c|c|c|}
\hline & $\begin{array}{c}\text { Usual care } \\
n=149\end{array}$ & $\begin{array}{c}\text { Telemonitoring } \\
n=157\end{array}$ \\
\hline Age (year) & $61.8[54.7 ; 66.1]$ & $60.8[53.8 ; 66]$ \\
\hline Male gender (n (\%)) & $111(74.5)$ & $115(73.2)$ \\
\hline BMI $\left(\mathrm{kg} / \mathrm{m}^{2}\right)$ & $31.4[28.1 ; 35.2]$ & $32.4[29.6 ; 36.5]$ \\
\hline $\mathrm{SBP}(\mathrm{mmHg})$ & $132[130 ; 140]$ & $140[130 ; 150]$ \\
\hline $\mathrm{DBP}(\mathrm{mmHg})$ & $80[70 ; 85]$ & $80[78 ; 90]$ \\
\hline \multicolumn{3}{|l|}{ History } \\
\hline Smoking (\%) & $72(48.6)$ & $92(58.6)$ \\
\hline Alcohol (\%) & $17(11.4)$ & $16(10.2)$ \\
\hline Gastroesophageal reflux (\%) & $28(18.8)$ & 25 (15.9) \\
\hline Type 2 Diabetes (\%) & $18(12.2)$ & 20 (12.9) \\
\hline Dyslipidemia (\%) & $71(50)$ & $61(39.4)$ \\
\hline Sedentarity (\%) & $31(20.8)$ & 34 (21.9) \\
\hline Depression (\%) & $21(14.2)$ & $25(16)$ \\
\hline \multicolumn{3}{|l|}{ Patient centered outcomes } \\
\hline Depression Scale & $3[1 ; 7]$ & $2[0 ; 5]$ \\
\hline Epworth Sleepiness Scale & $9[5 ; 14]$ & $9[5 ; 13]$ \\
\hline Pichot fatigue Scale & $11[4 ; 18.5]$ & $10[4 ; 18]$ \\
\hline \multicolumn{3}{|l|}{ Biological parameters } \\
\hline Fasting glucose $(\mathrm{g} / \mathrm{L})$ & $1.1[0.9 ; 1.3]$ & $1.1[1 ; 1.2]$ \\
\hline Cholesterol (g/L) & $2[1.6 ; 2.3]$ & $2[1.7 ; 2.4]$ \\
\hline HDL cholesterol (g/L) & $0.5[0.4 ; 0.6]$ & $0.5[0.4 ; 0.6]$ \\
\hline LDL cholesterol (g/L) & $1.2[0.9 ; 1.4]$ & $1.2[1 ; 1.5]$ \\
\hline Triglycerides (g/L) & $1.4[1 ; 1.7]$ & $1.5[1.1 ; 2]$ \\
\hline \multicolumn{3}{|l|}{ Respiratory parameters } \\
\hline AHI (events/hour) & $45[35.4 ; 61.2]$ & $47[35 ; 60.5]$ \\
\hline Mean nocturnal $\mathrm{SaO}_{2}(\%)$ & $92[90 ; 94]$ & $92.1[91 ; 94]$ \\
\hline $\mathrm{PaO}_{2}(\mathrm{mmHg})$ & $80[75 ; 87.1]$ & $80[72 ; 87]$ \\
\hline $\mathrm{PaCO}_{2}(\mathrm{mmHg})$ & $38[35 ; 41.4]$ & $38[36 ; 41]$ \\
\hline $\mathrm{pH}$ & $7.4[7.4 ; 7.5]$ & $7.4[7.4 ; 7.5]$ \\
\hline
\end{tabular}

AHI, apnea- hypopnoea index; DBP, diastolic office blood pressure; HDL, high-density lipoprotein; LDL, low-density lipoprotein; SBP, systolic office blood pressure. Data are median [25th ; 75th percentiles] or percentage. 
Table 2. Effect of multimodal telemonitoring and usual care on blood pressure

\begin{tabular}{|l|c|c|c|c|c|c|}
\hline \multirow{2}{*}{\multicolumn{1}{|c|}{$I T T$}} & \multicolumn{3}{|c|}{ Usual care $(\mathbf{n = 1 4 9 )}$} & \multicolumn{2}{c|}{ Telemonitoring (n=157) } \\
\cline { 2 - 7 } & $\mathbf{D 0}$ & $\mathbf{M 6}$ & $\mathbf{p}$-value & D0 & M6 & $\mathbf{p}$-value \\
\hline SHBP morning $(\mathbf{m m H g})$ & $134.95 \pm 20.14$ & $130.06 \pm 17.53$ & $\mathbf{0 . 0 0 0 1}$ & $135.16 \pm 18.15$ & $\begin{array}{c}130.98 \pm \\
18.47\end{array}$ & $\mathbf{0 . 0 0 2}$ \\
\hline DHBP morning $(\mathbf{m m H g})$ & $85.16 \pm 12.55$ & $80.74 \pm 10.92$ & $<\mathbf{0 . 0 0 0 1}$ & $85.93 \pm 12.34$ & $81.52 \pm 10.95$ & $<0.0001$ \\
\hline SHBP evening $(\mathbf{m m H g})$ & $130.42 \pm 17.29$ & $128.74 \pm 16.96$ & 0.24 & $130.63 \pm 18.21$ & $\begin{array}{c}128.84 \pm \\
17.64\end{array}$ & 0.13 \\
\hline DHBP evening $(\mathbf{m m H g})$ & $80.13 \pm 11.40$ & $78.19 \pm 10.70$ & $\mathbf{0 . 0 3}$ & $80.01 \pm 11.95$ & $78.04 \pm 10.82$ & $\mathbf{0 . 0 3}$ \\
\hline
\end{tabular}

DHBP, diastolic home self-measured blood pressure; SHBP, systolic home self-measured blood pressure. Data are mean \pm SD. 
Table 3. Effect of multimodal telemonitoring versus usual care on physical activity, BMI, patient centered outcomes and biological parameters

\begin{tabular}{|c|c|c|c|c|c|c|c|c|c|}
\hline & \multicolumn{4}{|c|}{ Usual care } & \multicolumn{4}{|c|}{ Telemonitoring } & \multirow{2}{*}{$\begin{array}{c}\text { p-value } \\
\text { between } \\
\text { the } 2 \text { groups }\end{array}$} \\
\hline & $\mathrm{n}$ & Do & M6 & p-value \# & $\mathrm{n}$ & Do & M6 & p-value \# & \\
\hline Number of steps / day & 28 & $5147.71 \pm 3068.81$ & $5242.60 \pm 3466.71$ & 0.92 & 27 & $4770.47 \pm 3515.17$ & $4994.62 \pm 3322.39$ & 0.77 & 0.83 \\
\hline BMI $\left(\mathrm{kg} / \mathrm{m}^{2}\right)^{*}$ & 114 & $31.1[27.8 ; 35.2]$ & $31.5[27.5 ; 35.3]$ & 0.77 & 110 & $32.0[29.1 ; 35.9]$ & $32.2[29.3 ; 36.1]$ & 0.13 & 0.40 \\
\hline Epworth Sleepiness Scale & 111 & $10.35 \pm 5.67$ & $6.05 \pm 4.07$ & $<0.0001$ & 108 & $9.40 \pm 4.38$ & $4.58 \pm 3.88$ & $<0.0001$ & 0.02 \\
\hline Pichot fatigue Scale & 110 & $11.93 \pm 8.18$ & $7.40 \pm 7.23$ & $<0.0001$ & 107 & $10.84 \pm 8.07$ & $5.4 \pm 6.07$ & $<0.0001$ & 0.06 \\
\hline Physical SF-12 & 92 & $44 \pm 5.9$ & $44.1 \pm 5.4$ & 0.81 & 80 & $43.8 \pm 5.9$ & $45.6 \pm 5.3$ & 0.01 & 0.05 \\
\hline Mental SF-12 & 92 & $42.7 \pm 6.2$ & $43.6 \pm 4.9$ & 0.28 & 80 & $42.6 \pm 5.3$ & $43.9 \pm 4.4$ & 0.05 & 0.67 \\
\hline Fasting glucose $(\mathrm{g} / \mathrm{L}) *$ & 99 & $1.07[0.94 ; 1.24]$ & $1.11[0.97 ; 1.28]$ & 0.96 & 90 & $1.07[0.99 ; 1.22]$ & $1.08[0.95 ; 1.24]$ & 0.88 & 0.89 \\
\hline Total cholesterol $(\mathrm{g} / \mathrm{L})$ * & 99 & $2.00[1.67 ; 2.36]$ & $1.92[1.62 ; 2.28]$ & 0.28 & 90 & $2.05[1.68 ; 2.40]$ & $1.97[1.64 ; 2.21]$ & 0.05 & 0.55 \\
\hline HDL cholesterol (g/L) * & 99 & $0.49[0.41 ; 0.60]$ & $0.48[0.43 ; 0.66]$ & 0.46 & 90 & $0.47[0.40 ; 0.55]$ & $0.50[0.40 ; 0.60]$ & 0.01 & 0.37 \\
\hline LDL cholesterol $(\mathrm{g} / \mathrm{L}) *$ & 99 & $1.22[0.95 ; 1.45]$ & $1.10[0.84 ; 1.43]$ & 0.01 & 89 & $1.19[0.98 ; 1.57]$ & $1.17[0.92 ; 1.41]$ & 0.10 & 0.54 \\
\hline Triglycerides $(\mathrm{g} / \mathrm{L}) *$ & 99 & $1.38[0.97 ; 1.74]$ & $1.32[0.93 ; 1.82]$ & 0.46 & 89 & $1.38[0.99 ; 1.89]$ & $1.23[0.89 ; 1.64]$ & 0.001 & 0.13 \\
\hline
\end{tabular}

BMI, body mass index; HDL, high-density lipoprotein; LDL, low-density lipoprotein. Data are mean \pm SD or median and interquartile range. \#: $p$-value of the difference between DO: baseline and M6: 6 months; *: nonparametric test; $n$ : number of complete cases 


\section{Figures legends}

Figure 1. Multimodal telemonitoring

\section{Figure 2. Study flow-chart}

Figure 3. Effect of multimodal telemonitoring and usual care on home self-measured blood pressures

DHBP, diastolic self-measured blood pressure; SHBP, systolic self-measured blood pressure; TM, telemonitoring; UC, usual care. Difference [95\% Cl]: difference between the telemonitoring group and usual care group in the differences between 6-month and baseline [95\% confidence interval] measurements.

Figure 4. Effect of multimodal telemonitoring and usual care on physical activity, quality of life, fatigue and somnolence

n (TM), number of complete cases in telemonitoring group; $n$ (UC), number of complete cases in usual care group; TM, telemonitoring; UC, usual care. Difference [95\% CI]: difference between the telemonitoring group and usual care group of the differences between 6-month and baseline [95\% confidence interval].

*for number of steps, physical and mental SF-12 the reference is usual care, for Epworth Sleepiness Scale and Pichot fatigue Scale the reference is telemonitoring. 


\section{Physiological}

sensors at home

Multidisciplinary

web platform medical chart

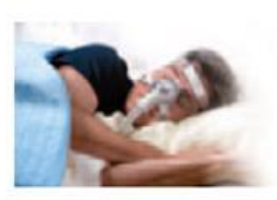

Compliance, leaks, residual events

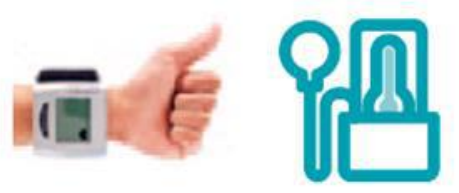

Home self-measurement of blood pressure

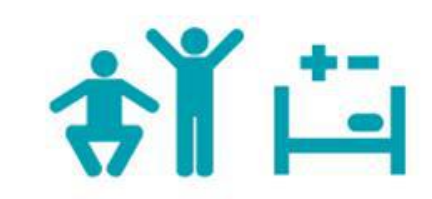

Physical activity / sleep duration

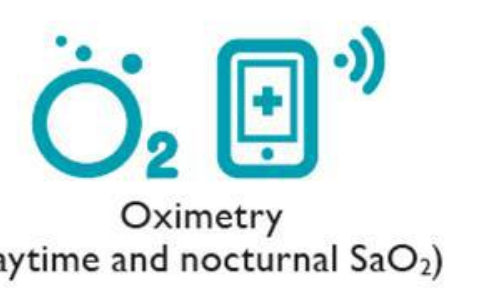

(daytime and nocturnal $\mathrm{SaO}_{2}$ )

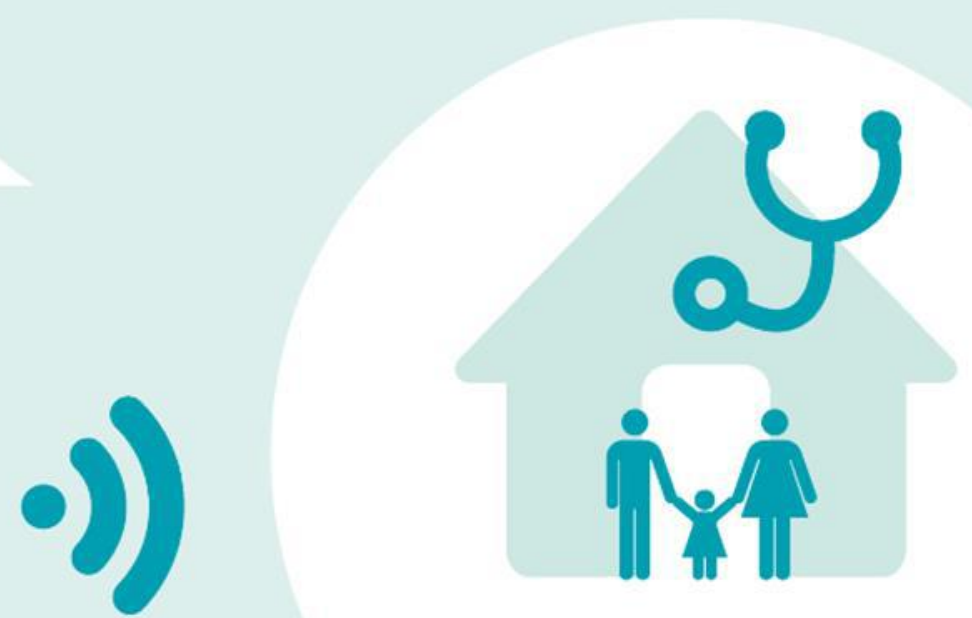

Access to home monitoring data for physicians and home care providers 


\section{6 severe OSA patients}

with high cardiovascular risk

Lost during follow-up

$n=27$

\section{CPAP}

Usual care

$n=149$
Intention-to-treat analysis
Lost during follow-up $n=40$ 
Effect

SHBP $(\mathrm{mmHg})$

Morning

Evening

DHBP $(\mathrm{mmHg})$

Morning

Evening

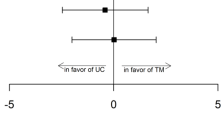

Difference $[95 \% \mathrm{Cl}] \mathrm{P}$-value

$\begin{array}{ll}-0.78[-3.91 ; 2.35] & 0.62 \\ -0.02[-3.10 ; 3.06] & 0.99 \\ -0.41[-2.46 ; 1.65] & 0.70 \\ 0.02[-2.00 ; 2.04] & 0.98\end{array}$




\section{Effect}

$\mathrm{n}$ (UC) $\mathbf{n}$ (TM)

Difference* $[95 \% \mathrm{CI}]$ P-value

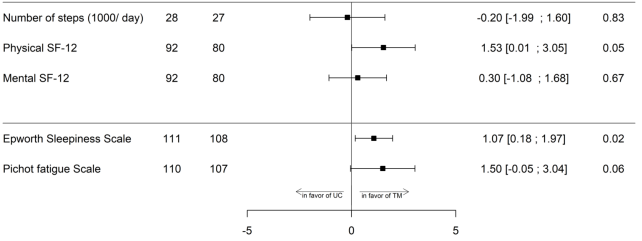

